\title{
Wind Turbine Controller Design for improved Fault Ride-Through Ability
}

\author{
Fan Zhang ${ }^{1, a^{*}}$ \\ ${ }^{1}$ A410, SGCC Park, Future Tech City, Beijing, China \\ azhangfan@sgeri.sgcc.com.cn,
}

\begin{abstract}
Keywords: DFIG, Fault ride-through, Crowbar, Wind turbine loads
Abstract. This paper presents a control strategy for wind turbines to enhance their fault ride-through capability. The controller design is based on pitch controlled variable speed wind turbine equipped with doubly-fed induction generator (DFIG). The fault ride-through is realized by injecting a crowbar with variable resistance on the generator rotor circuit. To reduce the mechanical loads induced by grid faults, the wind turbine controller is improved by means of filtering techniques which alleviate the loads on the turbine blades and drive-train. The performance of the control strategy is tested by simulation. It is shown that the combined mechanical and electrical controller design significantly improves the wind turbine fault ride-through capability. The effects of the fault ride-through strategy on both the wind turbine and electric network are then analysed.
\end{abstract}

\section{Introduction}

With the penetration level of wind power on electric network increasing rapidly all over the world, modern wind turbines are challenged to provide the same grid service as conventional power plants do. In the past few years many power system operators have revised their Grid Codes and set higher threshold for wind power integration [9]. Wind turbine design and control needs to be improved to optimize the compatibility between wind power and grid.

Among various requirements that wind turbine will have to meet in the future in the context of grid integration, the capability of wind farms to ride-through grid fault is of great importance and challenge. Grid faults cause transients not only in the electrical system, but also in the wind turbine mechanical system. From the electrical point of view, wind farms may lose power generation during grid fault, which deteriorates the fault and slows down the fault recovery. From the mechanical point of view, the grid disturbance causes wind turbine over speed and adds extra loads on wind turbine components. Severe grid faults may even lead to wind turbine emergent shut-down.

Variable speed wind turbine based on DFIG is currently the most popular wind energy generation system. The conventional way to protect this type of wind turbine from grid fault is by installing crowbar devices. The crowbar is capable of limiting the over voltage and current within the generator. However, the rotor circuit of the DFIG has to be short circuited by the crowbar during the grid fault which turns the DFIG into a squirrel cage induction generator (SCIG). The disadvantage of the crowbar protection is the control of the DFIG is completely lost due to the injection of the crowbar. The uncontrolled generator torque oscillation is transferred through the wind turbine drive-train and influence the wind turbine mechanical system and the power production is lost during fault. With high penetration level of wind power, the temporal lost of power generation can lead to large grid transients and disturbance on grid voltage and frequency [11].

There has been extensive research on the advanced crowbar scheme including the optimization of the crowbar resistance [1], active crowbar concept [7], flux damping during fault [8], Series connected crowbar [10] and etc. In the existing literature, the crowbar is only designed to protect the generator. The impact of the crowbar injection on the wind turbine mechanical components is not discussed. A crowbar with controllable resistance is proposed in this paper. The torque of wind turbine generator during grid fault is controlled by the crowbar.

The wind turbine controller is normally designed without the consideration of grid disturbances. It is observed that grid faults cause drive-train oscillation and frequent pitch action which would increase loads and reduce the life time of wind turbine. In this paper, the existing wind turbine torque control is 
modified to increase the drive-train damping during grid fault. The pitch control during grid fault is also optimized by filtering the pitch control signal according to the grid transients.

This paper is organized as follows. In section 2, the wind turbine and DFIG model are introduced first. Then, the variable crowbar resistance controller is presented in Section 3. In section 4, the existing wind turbine controller is improved to reduce the loads during grid fault. Lastly, the entire FRT strategy is tested by simulation. The effectiveness of the proposed control strategy is shown in simulation result and discussed.

\section{Modelling and control of wind turbine and DFIG}

Wind Turbine Drive-train Model. The full dynamic model of the wind turbine with its controller is described in [6]. The model is a $2 \mathrm{MW}$ variable speed pitch controlled wind turbine with maximum power tracking control under below rated wind speed and constant torque pitch control under above rated wind speed. The study in this paper only concerns the detail of the drive-train model.

To study the fault ride-through of wind turbine, the behaviour of drive-train needs to be investigated as it is connected directly to the generator and is affected by the power fluctuation in the grid. Typical wind turbine drive-train is composed by rotor hub, low speed shaft, gearbox, high speed shaft and generator rotor. The model of wind turbine drive train is represented in figure 1

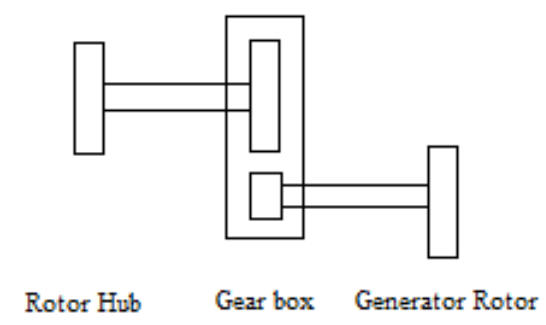

Figure 1: Wind turbine drive train.

The gear-train is represented in the low speed shaft for the convenience of model construction. The inertias of the low speed shaft and high speed shaft are incorporated into the inertias of rotor hub and generator rotor.

The aerodynamic torque produced by wind turbine on the low speed end of the drive-train is balanced by the generator reaction torque on the other end of the drive-train. The dynamics of the drive train are described by equation (1)

$$
\mathrm{I} \theta^{\prime \prime}=\mathrm{T}-\mathrm{T} 1-\gamma \theta^{\prime}
$$

where $\mathrm{T}$ and $\mathrm{T} 1$ are the hub torque and gear box torque at the low speed shaft end. I is the hub inertia plus the low speed shaft inertia, and $\theta$ is the angular displacement of the hub.

DFIG model. DFIG is currently the most popular generator topology for wind power generation because of its advantages such as decoupled control of real and reactive power and relatively low cost. The configuration of a typical DFIG is shown in Fig. 2. DFIG is essentially a would rotor induction generator where the rotor winding is connected to the grid through back-to-back converters.

In the synchronous reference frame fixed to stator flux, a third order DFIG model can be written as:

$$
\mathrm{Vds}=-\operatorname{RsIds}-\omega \mathrm{s} \varphi \mathrm{qs}+\varphi \mathrm{ds}
$$




$$
\begin{aligned}
& \text { Vqs }=- \text { RsIqs }-\omega s \varphi d s+\varphi q s \\
& \text { Vdr }=\operatorname{RrIdr}-s \omega s \varphi q r+\varphi d r \\
& \text { Vqr }=\operatorname{RrIqr}-s \omega s \varphi d r+\varphi q r
\end{aligned}
$$

where Vds and Vqs are $\mathrm{d}$ and $\mathrm{q}$ axis stator voltages, Ids and Iqs are $\mathrm{d}$ and $\mathrm{q}$ axis stator currents, Vdr and Vqr are $\mathrm{d}$ and $\mathrm{q}$ axis rotor voltage, Idr and Iqr are $\mathrm{d}$ and $\mathrm{q}$ axis rotor current, Rs and $\mathrm{Rr}$ are generator stator and rotor resistance. $\omega \mathrm{s}$ is the reference frame rotating speed, $\varphi \mathrm{ds}, \varphi \mathrm{qs}, \varphi \mathrm{dr}, \varphi q \mathrm{r}$ are stator and rotor flux on each axis.

The fluxes are calculated by the following equations

$$
\begin{aligned}
& \varphi \mathrm{ds}=- \text { LsIds + LmIdr } \\
& \varphi q s=- \text { LsIqs + LmIqr } \\
& \varphi d r=-\operatorname{Lr} * \operatorname{Idr}+\text { LmIds } \\
& \varphi q r=-\operatorname{Lr} * \text { Iqr + LmIqs }
\end{aligned}
$$

A crowbar is a set of resistor bank connected in series with generator through power electronic switches (IGBT) when the generator protection is activated. The conventional crowbar can be simply modelled as a resistor bank of fixed value. With the injection of the crowbar, the DFIG rotor resistance is changed from $\mathrm{Rr}$ to $\mathrm{Rr}+\mathrm{Rcrowbar}$.

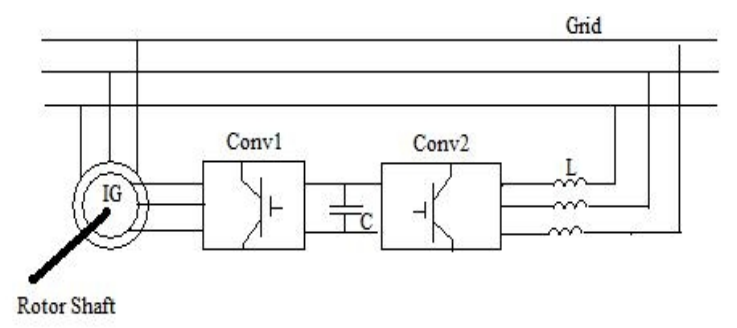

Fig. 2: Configuration of DFIG

DFIG control scheme. There are various control strategies for DFIG such as vector control, direct torque control, direct power control etc. One of the widely used DFIG control scheme known as current mode control is employed in this paper [2]. The q-axis rotor current is manipulated to control the reaction torque while the d-axis rotor current controls the reactive power generated. The control scheme relies on the operation of rotor side converter. The converter is short circuited from grid during faults with normal crowbar protection. Therefore, the control of DFIG by current mode control is lost when grid fault happens.

\section{Variable crowbar resistance control}

Research has been carried out on DFIG rotor resistance control [10]. A constant resistor is connected to protect the generator from over current. The controller performance was acceptable when the task was preventing the DFIG from disconnection during grid disturbance. However, the requirement for wind turbine fault ride-through is likely to be increased in the near future due to the raise of wind power penetration level. It is reported in [11] that the loss of wind farm power generation has caused voltage and 
system frequency excursion. It is also noticed that the low generator torque under traditional protection scheme leads to extra loads on wind turbine. The problem will be more severe with the increase of wind turbine size. Therefore, a DFIG controller which is able to keep producing demanded torque and power during grid fault is developed by using a crowbar with variable resistance. The configuration of the proposed FRT controller is shown in Fig. 3.

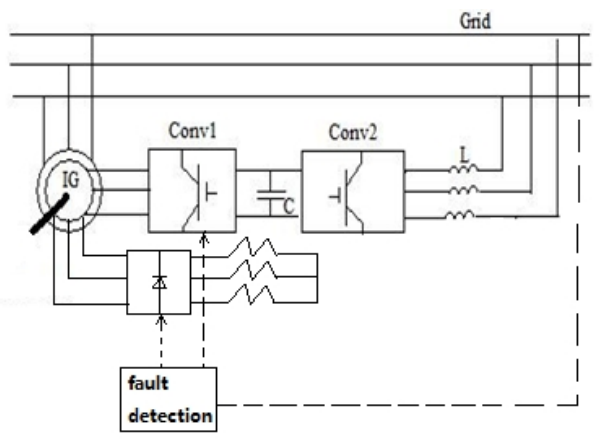

Fig. 3: DFIG with variable crowbar resistance control

The fault detection unit measures the grid voltage for the controller switching. In normal operation DFIG controller is activated with the crowbar bypassed. When grid voltage falls below a certain level, depending on the Grid Code requirement, the unit sends signals both to wind turbine converter to shut it down and to the crowbar rectifier and IGBT switch to inject the resistor bank.

Feed-forward control is applied to regulate the crowbar resistance as the parameters of DFIG are normally given by manufactures or measurable. Therefore, the feed-forward control based on generator parameters gives the best performance. The optimal crowbar resistance can be directly calculated from the machine parameters according to the reference torque. A PID controller also shows satisfactory performances but the response speed is slower than the proposed controller. The scheme of the controller is shown is Fig. 4

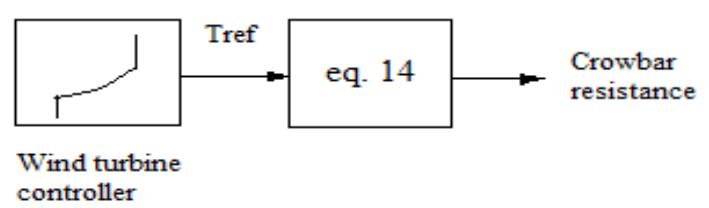

Fig. 4: Variable crowbar resistance scheme

Optimal crowbar resistance determination. When grid fault occurs, the converter systems are short circuited due to initial over-current. The DFIG can be considered simply as an induction machine. The Thevinin equivalent circuit of such machine is shown in Fig. 5. 


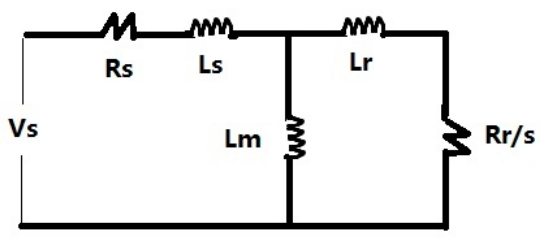

Fig. 5: Equivalent circuit of induction generator

Where Vs is the terminal voltage, Rs is the stator voltage, Ls is the stator inductance, Lm is the mutual inductance, $\mathrm{Lr}$ is the rotor inductance. $\mathrm{S}$ is the generator slip

The generated torque is calculated as

$\mathrm{T}=3 \operatorname{PfRrIr} 2 / 2 \mathrm{~s} \omega \mathrm{s}$

Where Pf is the power factor and $\omega s$ is the rotating speed of generator.

From the equivalent circuit, the rotor current can be derived as

$\mathrm{Ir}=\mathrm{Vs} /(\mathrm{Rs}+\mathrm{Rr} / \mathrm{s}+\mathrm{j}(\mathrm{Ls}+\mathrm{Lr}))$

The generator torque equation is obtained by substituting (11) into (10)

$\mathrm{T}=3 \mathrm{PfRrVs} 2 / 2 \mathrm{~s} \omega \mathrm{s}[(\mathrm{Rs}+\mathrm{Rr} / \mathrm{s}) 2+(\mathrm{LsLr}) 2]$

It is noticed that in the give reference frame, the generator torque is only controlled by q-axis current. The produced torque can also be written as [2]:

$$
\mathrm{T}=-\mathrm{LmVsIqr} / \mathrm{Ls}
$$

By substituting (13) into (4) with the rotor flux equation (6) (8), the rotor resistance in terms of demanded torque is calculated as:

$$
\mathrm{Rr}=-\mathrm{s}[\mathrm{VsLm} / \mathrm{Ls}+\mathrm{Idr}(\mathrm{Lr}-\mathrm{Lm} 2 / \mathrm{Ls})] /(\operatorname{TrefLs} /(\mathrm{LmVs}))
$$

The demanded rotor resistance is significantly larger than the induction machine rotor resistance. Therefore, the resistance of the series connected crowbar is varied to achieve the rotor resistance control.

Switching strategy. The efficiency of the proposed controller is limited by several factors. The grid voltage level at PCC is a major limitation on the controller performance. From equation (12) it can be easily derived that the maximum generator torque, which is also called pull-out torque, is proportional to Vs2. Therefore the generator is not able to produce required torque under extremely low voltage. The rotational speed of the DFIG also has influence on the controller operation. A switching strategy for the FRT controller is developed.

The controller requires the monitoring of several variables due to the limiting condition stated above. Both the grid voltage and wind turbine high speed shaft rotating speed are measured. The FRT controller takes over the control of wind turbine generator when the DFIG protection system is triggered by the grid fault. The grid-side converter current is chosen as the switching reference of the FRT controller as the DFIG converter is disconnected from the grid after grid fault and the grid side converter current drops to zero immediately. 
When grid fault happens, the generator speed is compared with the synchronous speed first. If the generator speed is greater, the controller will calculate the optimal resistance of the crowbar. Otherwise the crowbar of a fixed resistance will be injected to increase generator damping. With sufficient converter rating, the nominal speed of DFIG can be set at a low level so the DFIG works in generator mode during most time.

The first step for crowbar resistance control is to determine if the generator is able to produce the demanded torque. The maximum torque under certain voltage is limited by the torque-slip curve of an induction machine. It can be calculated from equation (12). The reference signal will be set to the maximum torque available according to the grid voltage. If the demanded torque cannot be achieved, the crowbar resistance which produce the maximum available torque will be injected. If the demanded torque can be achieved, the crowbar with the optimal resistance will be connected. The grid voltage is always measured during the fault. The DFIG controller will be switched on with crowbar disconnected when the fault is recovered and the grid voltage returns to the acceptable value. The flow chart of the FRT control strategy is shown in Fig 6

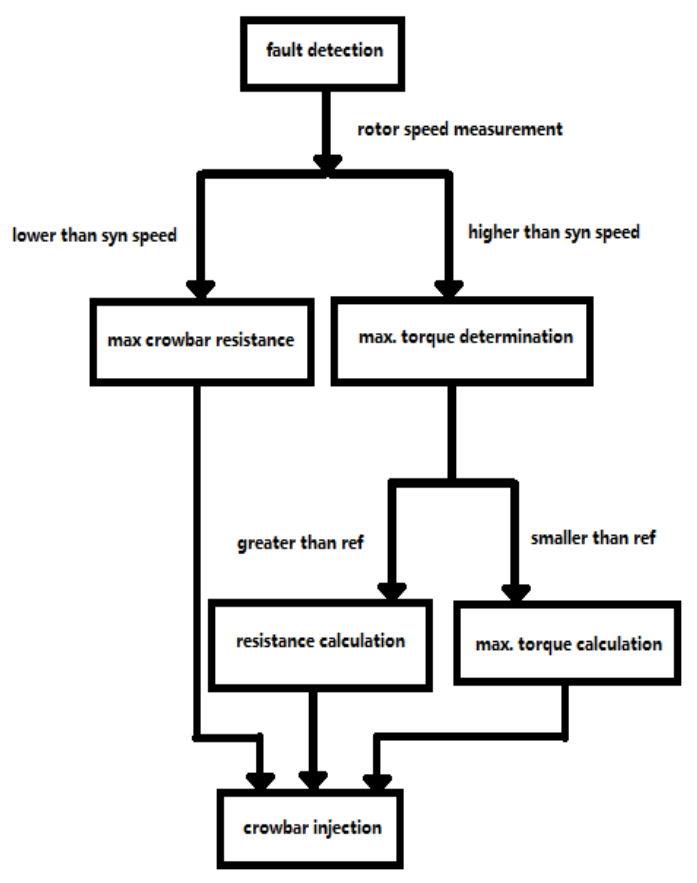

Fig. 6: Flow chart of variable crowbar resistance control

\section{Wind turbine load alleviation during grid fault}

Active drive-train damping. The wind turbine generator operates as an induction generator during grid fault. Such machine provides large damping to wind turbine drive-train because the generator torque increases rapidly with the generator speed according to the torque-speed characteristic of induction generator. The generator switches back to DFIG mode after fault clearance. The damping under this mode is much smaller since the generator torque is controlled by DFIG controller rather than regulated by torque-slip curve. The generator experiences large torque variation between the mode switch which creates large torque oscillation on the drive-train. The oscillation is to be damped to avoid the structural loads on wind turbine and rotor speed excursion. 
Drive-train damping filter (DDF) is a widely used application to reduce the loads on the drive-train [7]. The DDF is basically a band pass filter sitting on the drive-train first dynamic mode frequency. The wind turbine torque demand is slightly modified by the filter to increase drive-train damping. The drive-train damping filter is normally tuned for wind turbine normal operation. However, the vibration induced by grid fault is much larger than the vibration induced by wind speed variation. The conventional DDF is not able to produce enough damping for wind turbine drive-train during grid fault.

In [5] a PI controller is developed to reduce the post fault drive-train oscillation. The controller employs the generator torque to regulate drive train torque, which is similar to DDF but the interaction between the speed controller and DDF, which is applied on most commercial wind turbines, is not discussed.

A drive-train filter to increase the damping during grid fault is proposed. The DDF concept is applied with modifications. It is shown in (12) that the torque oscillation is proportional to Vs2. It is given in (1) that the acceleration/deceleration speed of the wind turbine drive-train is also proportional to torque variation. Therefore the value of Vs2 is used as an index of drive-train filter gain. The filter operates as DDF during normal operation of wind turbine. When grid voltage dip is detected, the filter gain varies according to the value of voltage dip level. The drive-train damping is temporally increased during grid fault without implementing extra devices.

Pitch load alleviation filter. The pitch controller aims to keep the wind turbine rotating speed constant under above rated wind speed. In case of grid fault, the wind turbine generator loses its reaction torque which causes the turbine to speed up. Unlike the wind speed variation, the torque oscillation caused by grid fault is of large magnitude in short time. Due to the large time constant of wind turbine, the pitch control cannot effectively reduce the speed oscillation caused by grid faults but only increase the load on wind turbine blade. A filter is added to pitch control loop to avoid the excessive pitch action when grid fault happens. The pitch and torque control configuration is shown in Fig. 7. The torque control works normally trying to reduce the fault transients while the pitch control only regulates the input power.

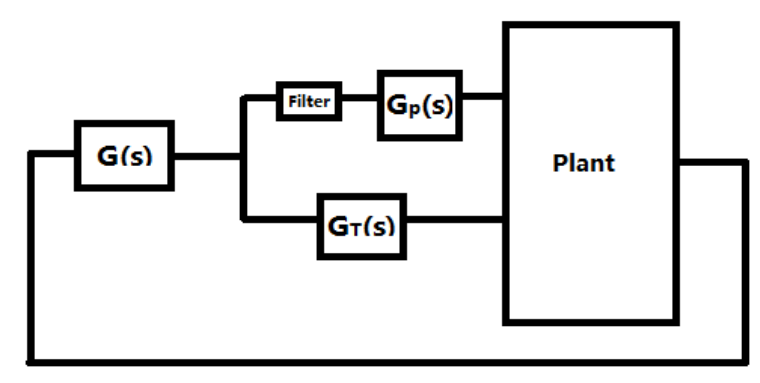

Fig. 7: Configuration of pitch load alleviation filter

The filter is essentially a band-pass filter centred at the generator rotor shaft oscillation frequency with a large gain and relatively narrow peak. Hence, only the pitch action induced by grid fault is bypassed. The pitching according to wind speed variation is not influenced. The filter should only be injected when significant voltage drop is detected to avoid the impact on wind turbine normal operation.

\section{Simulation Result}

The proposed wind turbine FRT control strategy is tested by simulations. The simulation is carried out based on the wind turbine model described in [6] and the generic grid model in [3]. At first the performance of the variable crowbar resistance control, active drive-train damping and pitch filter are 
tested separately. Then the wind turbine with FRT controller is connected to the grid model. A grid fault is applied and the performance of the FRT control strategy is shown.

Performance of variable crowbar resistance control. Results from variable crowbar resistance control are presented in Fig. 8 and Fig. 9. A 50\% voltage dip is applied at the DFIG terminal with the average effective wind speed being $10 \mathrm{~m} / \mathrm{s}$ on the wind turbine. The crowbar short circuited the rotor side converter immediately after the fault. It can be seen from the plot that the DFIG is able to produce the demanded electrical torque under the given condition. The rotor speed oscillation is effectively reduced by the injection of the crowbar.

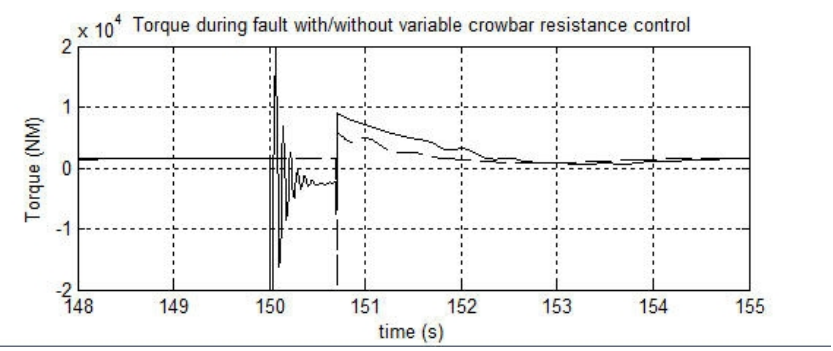

Fig. 8: DFIG torque under fault

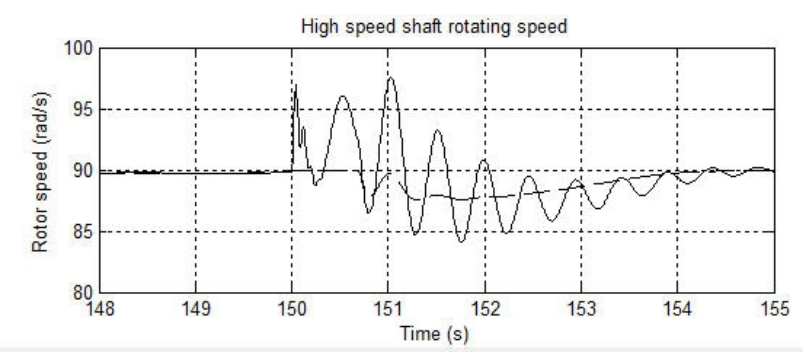

Fig. 9: Wind turbine high speed shaft speed under fault

Solid line: Wind turbine with normal control

Dashed line: Wind turbine with variable crowbar resistance control

\section{Wind turbine loads alleviation during fault}

The wind turbine drive-train speed during grid fault is presented in Fig. 10. A 100\% voltage dip is applied. The result shows that the drive-train oscillation is effectively damped by the proposed active drive-train damping filter. Fig. 11 and Fig. 12 illustrates the pitch angle of wind turbine during a grid fault. The pitching of the wind turbine rotor is reduced by the pitch filter while the generator speed remains the same. 


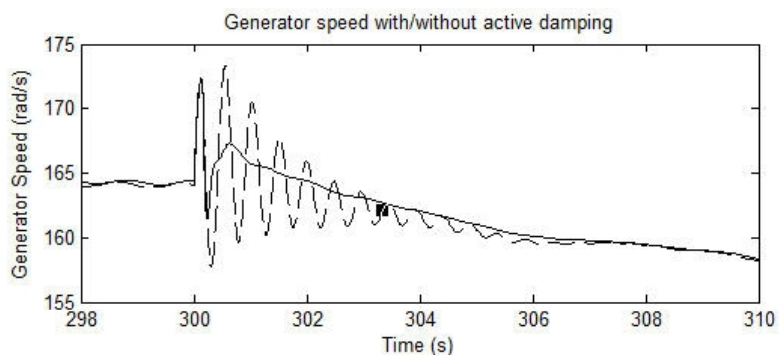

Fig. 10: Generator speed during grid fault

Solid line: Wind turbine with active drive-train damping filter

Dashed line: Wind turbine with conventional DDF

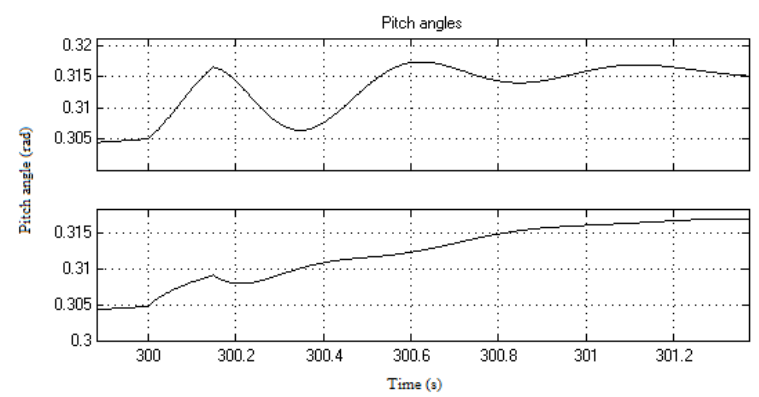

Fig. 11: Pitch angle during fault

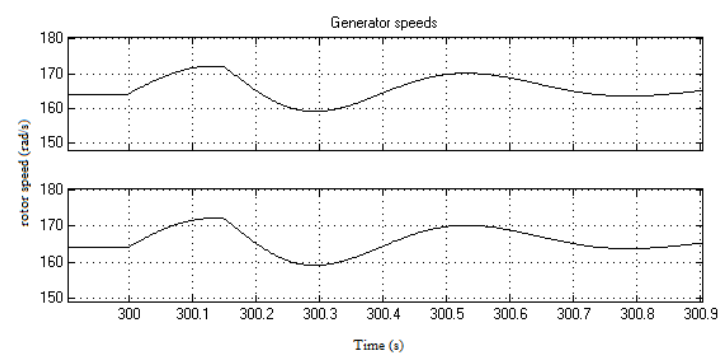

Fig. 12: generator speed during fault

Impact of proposed control strategy on grid. The proposed full wind turbine FRT control strategy is tested in a generic grid model shown in Fig. 13. The influence of successful wind turbine FRT on the local grid is shown in Fig. 14 and Fig. 15. It can be seen from the result that the FRT of wind farm is able to reduce the fault current at wind farm and improve the voltage fluctuation at a nearby conventional power plant. 


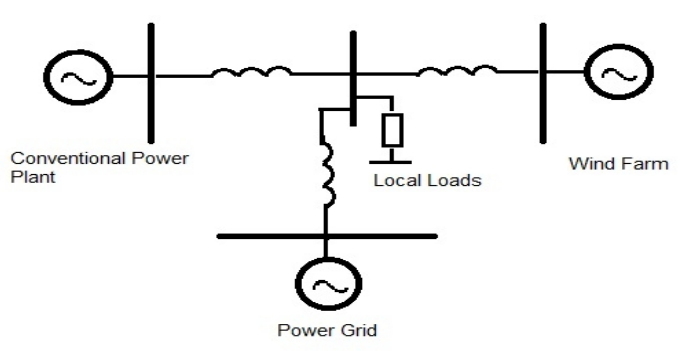

Fig. 13: Generic network model

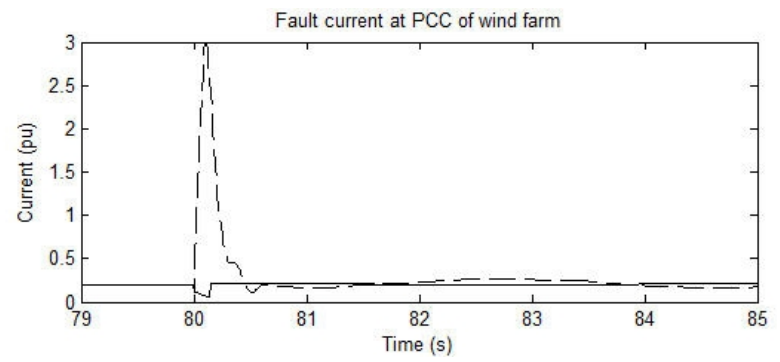

Fig. 14: Fault current at wind farm

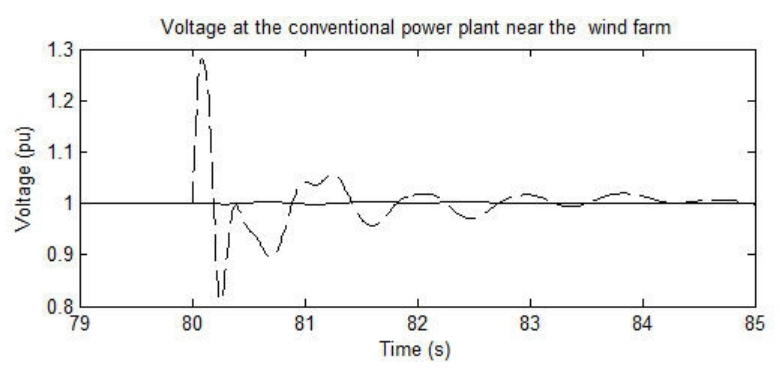

Fig. 15: Voltage at PCC of the conventional power plant

\section{Conclusion}

This paper presents a FRT strategy for MW scale wind turbines. To the author's knowledge most wind turbine FRT strategy only focuses on wind turbine protection rather than sustained operation and grid support during grid fault. The aim of the FRT strategy developed in this paper is to keep the power production while reducing the loads on wind turbine when fault happens. The investigation is focused on the interaction between wind turbine mechanical and electrical systems. The FRT problems from both sides are considered.

The proposed control strategy is tested with simulation. Both the wind turbine and electrical equipments are modelled in detail therefore the interaction between them is shown clearly in the simulation results. It is proved by the simulation result that at the wind turbine end, the normal operation is protected from the transients caused by grid disturbances. The electrical torque oscillations are eliminated by the variable crowbar resistance control. Under extreme conditions when crowbar is not able to completely recover the generator torque, the filter designed for both the torque control and pitch 
control prevents the wind turbine from experiencing large loads. A case study with a fault in a generic grid shows that at the grid end, the wind farm with proposed controller is able to keep its generation during the fault. Thereby assist the ride-through of nearby power plant and improve the condition of the local grid.

\section{References}

[1] Olimpo Anaya-Lara, Zifa Liu , Gustavo Quinonez-Varela and James R. McDonald, "Optimal DFIG Crowbar Resistor Design under Different Controllers during Grid Faults," Third International Conference on electric Utility Deregulation and Restructuring and Power Technologies, 2008.

[2] Olimpo Anaya-Lara, F.Michael Hughes, Nicholas Jenkins, Goran Strbac, "Rotor flux magnitude and angle control strategy for doubly fed induction generators," Wind energy. 2006; 9: 479-495.

[3] Olimpo Anaya-Lara, M. Hughes, and N. Jenkins, "Generic network model for wind farm control scheme design and performance assessment," in Proc. Eur. Wind Energy Conf., London, UK, 2005.

[7] Tony Burton, David Sharpe, Nick Jenkins, Ervin Bossanyi, Wind energy handbook.

[5] Anca D. Hansen, Gabriele Michalke, "Fault ride-through capability of DFIG wind turbines," Renewable Energy. 32 (2007) 1549-1610

[6] W.E. Leithead and M.C.M. Rogers,, "Drive-train characteristics of constant speed HAWTs," Wind Engineering. Vol 20. No. 3, 1996

[4] J.Morren and S.W.H. de Haan, "Ridethrough of wind turbines with doubly-fed induction generator during a voltage dip," IEEE Trans. Energy Convers., vol. 20, no. 2, pp. 435-441, Jun. 2005

[8] Miguel Rodriguez, G Abad, I Sarasola, A Gilabert, "Crowbar Control Algorithms for Doubly Fed Induction Generator During Voltage Dips," 2005 European Conference on Power Electronics and Application, 10 pp. - P.10

[9] M. Tsili, C. Patsiouras, and S. Papathanassiou, "Grid code requirements for large wind farms: A review of technical regulations and available wind turbine technologies," in Porc. Euro. Wind. Energy. Conf. Expo., Mar/Apr. 2008, pp. 1-11

[10] Jin Yang, John E. Fletcher, John O'Reilly, “A series-dynamic-resistor-based converter protection scheme for doubly-fed induction generator during various fault conditions," IEEE Trans. Energy Conv. Vol. 25, No. 2, Jun. 2010

[11] "Reports on three grid faults caused by wind farm disconnection."in http://www.serc.gov.cn/ywdd/201105/t20110506_14631.htm. 